\title{
Risk factors associated with primary and secondary infertility in eastern part of north India: A pilot study
}

\author{
Lavina Chaubey ${ }^{1, *}$, T.B. Singh ${ }^{2}$, Kirti Kaithwas ${ }^{3}$, Namita Doharey ${ }^{4}$, Shilpa Chowdary Peddappolla ${ }^{5}$ \\ ${ }^{\mathbf{1}}$ Assistant Professor, ${ }^{2}$ Professor, ${ }^{3-5}$ Junior Resident, ${ }^{\mathbf{1} 3-5}$ Dept. of Obstetrics \& Gynecology, ${ }^{2}$ Dept. of Community Medicine, Institute of \\ Medical Sciences, Banaras Hindu University, Varanasi, Uttar Pradesh, India \\ *Corresponding Author: Lavina Chaubey \\ Email: lavinachaubey@gmail.com
}

\begin{abstract}
Introduction: Infertility is defined as the failure to achieve clinical pregnancy after 12 months or more of regularly unprotected sexual intercourse. According to a systematic analysis of National Health Survey-2010, approximately $10.5 \%$ of women around the world experienced secondary infertility and roughly $2 \%$ experienced primary infertility.

Objectives: To analyse the risk factors for infertility in eastern part of North India.

Materials and Methods: This cross-sectional, analytical pilot study was done from January 2018 to March 2018 as a schedule based survey involving 65 couples with infertility attending Sir Sunderlal hospital, Varanasi, U.P., that primarily caters to patients from eastern part of north India. Sixty valid couples were analysed.

Results: Seventy per cent couples resided in eastern U.P. and $60 \%$ belonged to middle socioeconomic status. Treatment was sought $\geq 3$ years by $86.7 \%$. Among a total number of 60 females partners in their reproductive age (15-49 years), 31 (51.7\%) had primary infertility and $29(48.3 \%)$ had secondary infertility. The age group of $27-38$ years comprised of $53.3 \%$ females and $65.6 \%$ of these had secondary infertility. Those females with regular menstrual cycles had a predominance of primary infertility (70\%) and irregular cycles was associated more with secondary infertility $(66.7 \%)$.

Conclusion: Association of primary and secondary infertility was found with age \& menstrual irregularity, hence these may be considered as risk factors. BMI and amount of menstrual flow were not significantly associated with either types of infertility and need further evaluation in a larger study.
\end{abstract}

Keywords: Primary infertility, Secondary infertility, Risk factors, North India.

\section{Introduction}

Infertility is defined as the failure to achieve clinical pregnancy after 12 months or more of regularly unprotected sexual intercourse. ${ }^{1}$ According to a systematic analysis of National Health Survey-2010, approximately $10.5 \%$ of women around the world experienced secondary infertility, and roughly $2 \%$ experienced primary infertility. ${ }^{2}$ The prevalence of secondary infertility, in particular, varies widely by region and country, ranging from less than $6 \%$ to greater than $16 \%$ of women. However, comprehensive epidemiological studies on the risk factors for infertility are not well documented ${ }^{3,4}$ and although parameters such as age, obstetrical history, smoking patterns, menstruation, BMI index, lifestyle and environmental factors are traditionally considered to be the major risk factors leading to infertility, ${ }^{5}$ it is worth finding out the specific risk factors in certain defined regions. In this pilot study, an analysis of the risk factors in infertile couples from eastern part of north India was done in order to create a platform for a study of much larger magnitude, involving at least 1500 couples, so as to provide guidance for further prevention of infertility.

\section{Materials and Methods}

The study was approved by the Ethics Committee of Institute of Medical Sciences, Banaras Hindu University, Varanasi, India and all participants signed the consent forms.

The study population in this schedule based crosssectional, analytical pilot study comprised of 60 couples recruited from the gynecology out-patient department of Sir
Sunderlal Hospital, Institute of Medical Sciences, Banaras Hindu University in Varanasi (U.P.) India, from January to March 2018.

Inclusion Criteria of couples was as stated below:

1. Reproductive age group of 15-49 years

2. In de facto marriage

3. Presence of history of infertility, primary or secondary, as defined by $\mathrm{WHO}^{1}$.

Exclusion Criteria was as stated below:

1. Couples not living together for a period of more than 6 months

2. Divorced or widowed

3. Not residing in eastern part of north India.

In the present study, a self-designed schedule was employed to collect the following information:

General Demographic Information: Age, address, occupation, religion, socioeconomic status (Kuppuswamy scale) and diet. BMI was calculated as weight in kilograms divided by the square of the height in metres $(\mathrm{kg} / \mathrm{m} 2)$ according to the WHO criteria, which defined underweight as less than $18.5 \mathrm{~kg} / \mathrm{m} 2$; moderate as $18.5-24.9 \mathrm{~kg} / \mathrm{m} 2$; overweight as $25.0-29.9 \mathrm{~kg} / \mathrm{m} 2$; obese as $\geq 30 \mathrm{~kg} / \mathrm{m} 2{ }^{6}$

Marriage and Childbearing Status: Age at marriage, years since marriage, parity, prior antenatal care received, complications in previous pregnancies, history of prior procedures like caesarean sections and dilatation \& curettage.

Type of infertility and prior treatment for infertility. The WHO definition of infertility was used and defined as the failure to achieve a clinical pregnancy after 12 months or 
more of regularly unprotected sexual intercourse. Female primary infertility defined as women who have never been pregnant or given birth after sexual maturity. Female secondary infertility: women who are having difficulty in becoming pregnant with previous successful delivery. ${ }^{1}$

Menstruation Status: Amount of bleeding, whether cycles were regular or irregular, the presence or absence of amenorrhoea, dysmenorrhoea, and dyspareunia. According to the Williams Gynecology definition, normal menstrual blood volume is 30 to $50 \mathrm{ml}$, while $20 \mathrm{ml}$ or less is considered as scanty and more than $80 \mathrm{ml}$ is defined as excessive menstruation.

Associated Medical Problems: Vaginal discharge, past medical disease history.

\section{Statistical Analysis}

Analysis of data collected was done with the Pearson chi square test using the SPSS software trial version 20 .

\section{Results}

Demographic characteristics of the study subjects

Table 1: Distribution of females according to age and type of infertility

\begin{tabular}{|l|c|c|c|}
\hline \multirow{2}{*}{$\begin{array}{c}\text { Age group } \\
\text { (In years) }\end{array}$} & \multicolumn{2}{|c|}{ Type of Infertility } & \multirow{2}{*}{ Total (\%) } \\
\cline { 2 - 3 } & Primary N (\%) & Secondary N (\%) & \\
\hline $\mathrm{A}(15-26)$ & $18(72.0)$ & $07(28.0)$ & $25(41.7)$ \\
\hline $\mathrm{C}(27-38)$ & $11(34.4)$ & $21(65.6)$ & $32(53.3)$ \\
\hline Total & $02(66.7)$ & $01(33.3)$ & $03(5.0)$ \\
\hline Mean $\pm \mathrm{sd}$ & $31(51.7)$ & $29(48.3)$ & $60(100)$ \\
\hline
\end{tabular}

$$
X^{2}=5.76, d f=1, p=0.0163, t=2.77, p=0.008
$$

Table 1 out of the total number of 60 infertile females partners of couples between 15-49 years, 31 (51.7\%) had primary infertility and $29(48.3 \%)$ had secondary infertility.

The age distribution of the study group was divided into three, $\mathrm{A}=15-26$ yrs., $\mathrm{B}=27-38$ yrs. and $\mathrm{C}=39-49$ yrs.

Group A (15-26 yrs.) had $25(41.7 \%)$, group B had 32 $(53.3 \%)$ and group $\mathrm{C}$ had only $3(5.0 \%)$ females partners out of a total of 60 .
Among 25 females partners between 15-26 years of age (gourp A), 18 (72.0\%) had primary infertility and only 7 $(28.0 \%)$ had secondary infertility, where as in the age group of 27-38 years (group B) only $11(34.4 \%)$ had primary infertility as against $21(65.6 \%)$ cases of secondary infertility.

Table 2: Distribution of couples according to states and type of infertility

\begin{tabular}{|l|c|c|c|}
\hline \multirow{2}{*}{ States } & \multicolumn{2}{|c|}{ Type of Infertility } & \multirow{2}{*}{ Total (\%) } \\
\cline { 2 - 3 } & Primary N (\%) & Secondary N (\%) & \\
\hline Bihar & $07(50.0)$ & $07(50.0)$ & $14(23.3)$ \\
\hline Eastern U.P. & $20(47.6)$ & $22(52.4)$ & $42(70.0)$ \\
\hline Others* & $04(100)$ & $00(0.0)$ & $04(6.7)$ \\
\hline Total & $31(51.7)$ & $29(48.3)$ & $60(100)$ \\
\hline
\end{tabular}

$\mathrm{X}^{2}=4.03, \mathrm{p}=0.13, *$ Includes Jharkhand, Madhya Pradesh, West Bengal

As seen from Table 2, $42(70 \%)$ of 60 infertile couples resided in Eastern U.P., 14 (23.3\%) in Bihar and only 4 $(6.7 \%)$ were from various others eastern parts of north India.
The distribution of primary and secondary infertility in couples is almost equal, $20(47.6 \%)$ and $22(52.4 \%)$ from eastern U.P., 7 and 7 (50.0\%) from Bihar.

Table 3: Distribution of socioeconomic status, female partner BMI, years since marriage with type of infertility

\begin{tabular}{|c|c|c|c|c|}
\hline \multirow{2}{*}{$\begin{array}{l}\text { Socioeconomic Status } \\
\text { (Kuppuswamy Scale) }\end{array}$} & \multicolumn{2}{|c|}{ Type of Infertility } & \multirow{2}{*}{ Total (\%) } & \multirow{2}{*}{$X^{2}, p$ value } \\
\hline & Primary N (\%) & Secondary N (\%) & & \\
\hline Lower & $05(71.4)$ & $02(28.6)$ & $07(11.7)$ & \multirow{3}{*}{$\begin{array}{c}\mathrm{X}^{2}=1.28 \\
\mathrm{df}=2 \\
\text { p. }=0.53\end{array}$} \\
\hline Middle & $18(50.0)$ & $18(50.0)$ & $36(60.0)$ & \\
\hline Upper & $08(47.1)$ & $09(52.9)$ & $17(28.3)$ & \\
\hline $\boldsymbol{B M I}\left(\right.$ WHO Criteria $\left.{ }^{6}\right)$ & & & & \multirow{3}{*}{$\begin{array}{c}\mathrm{X}^{2}=0.52 \\
\mathrm{df}=1 \\
\mathrm{p}=0.47\end{array}$} \\
\hline Normal, $18.5-24.9 \mathrm{~kg} / \mathrm{m} 2$ & $21(47.7)$ & $23(52.3)$ & $44(73.3)$ & \\
\hline Abnormal* & $10(62.5)$ & $06(37.5)$ & $16(26.7)$ & \\
\hline Years since marriage & & & & \multirow{3}{*}{$\begin{array}{c}\mathrm{X}^{2}=0.078 \\
\text { Df }=1 \\
\mathrm{P}=0.78\end{array}$} \\
\hline$<3$ years & $05(62.5)$ & $03(37.5)$ & $08(13.3)$ & \\
\hline$\geq 3$ years & $26(50.0)$ & $26(50.0)$ & $52(86.7)$ & \\
\hline
\end{tabular}

* Abnormal include underweight, overweight and obese 
In table 3 , it is clearly seen that $36(60.0 \%)$ couples out of total 60 were of middle socioeconomic status (Kuppuswamy scale), 17 (28.3\%) were upper status, whereas only $7(11.7 \%)$ were from lower status. The distribution of primary and secondary infertility is almost equal among the upper and middle status groups.

This table also shows that 44 (73.3\%) female partners had normal BMI with an equal distribution of primary and secondary infertility. Among cases with abnormal BMI, $62.5 \%$ had primary infertility.

There were only 8 couples out of 60 who sought help for infertility at less than 3 years of marriage whereas 52 $(86.7 \%)$ sought help at 3 or more years of marriage. Among these 52, primary and secondary infertility was equally distributed.

Table 4: Distribution of menstrual flow and regularity of cycles with type of infertility

\begin{tabular}{|c|c|c|c|c|}
\hline \multirow[t]{2}{*}{ Menstrual flow } & \multicolumn{2}{|c|}{ Type of Infertility } & \multirow{2}{*}{ Total (\%) } & \multirow{2}{*}{$\mathbf{X}^{2}, \mathbf{p}$ value } \\
\hline & Primary N (\%) & Secondary N (\%) & & \\
\hline Scanty/amenorrhoea & $13(50.0)$ & $13(50.0)$ & $26(43.3)$ & \multirow{3}{*}{$\begin{array}{c}\mathrm{X}^{2}=0.085 \\
\mathrm{Df}=2 \\
\mathrm{P}=0.96\end{array}$} \\
\hline Normal & $13(52.0)$ & $12(48.0)$ & $25(41.7)$ & \\
\hline Excessive & $05(55.6)$ & $04(44.4)$ & $09(15.0)$ & \\
\hline \multicolumn{4}{|l|}{ Regularity of cycles } & \multirow{3}{*}{$\begin{array}{c}X^{2}=6.67 \\
d f=1 \\
p=0.009\end{array}$} \\
\hline Regular & $21(70.0)$ & $09(30.0)$ & $30(50.0)$ & \\
\hline Irregular & $10(33.3)$ & $20(66.7)$ & $30(50.0)$ & \\
\hline
\end{tabular}

Table 4 shows that among 60 females partners, scanty flow/amenorrhoea was found in $26(43.3 \%)$, whereas an almost equal number, $25(41.7 \%)$ had no menstrual problems. Only $9(15.0 \%)$ had excessive bleeding

With regards to menstrual cycles, the two groups of females with regular and irregular cycles had an equal number of 30 subjects. Amongst those with regular cycles, primary infertility was more common $(21,70.0 \%)$ and in those with irregular cycles, secondary infertility predominated $(20,66.7 \%)$

\section{Discussion}

There have been many studies in the past investigating the incidence and prevalence of infertility in various geographical parts of the world but there is a paucity of literature regarding specific risk factors associated with infertility and its types. In 2016, the estimated overall median prevalence of infertility in developed and less developed countries was $9 \% .^{8}$ In 2015 , a study from Iran reported the overall prevalence of primary infertility among couples as $17.3 \% .^{9}$ In comparison, a survey done way back in 2007 in India, the incidence of infertility was found to be $14.2 \%$ among Khairwar tribe. However, these studies did not separately mention regarding the type of infertility (primary or secondary) or their associated risk factors. ${ }^{7}$ A review done in 2015 , showed that about $8 \%$ of currently married women in India experienced infertility during their reproductive life period and among them majority suffered from secondary infertility (5.8\%).$^{10}$ However, here too, risk factors leading to specific infertility were not mentioned.

This pilot study was done to find what risk factors are associated with the types of infertility (primary or secondary) in the eastern part of north India, since no such data was available from this region. Sixty couples seeking help for infertility were included based on complete response to our self-designed schedule survey. Among these, primary infertility was found to be $51.7 \%$ (31 couples) as against the secondary infertility, 48.3\% (29 couples) which showed an equal distribution. When analysed against the 3 categories of reproductive age groups, that is, 15-26 (early), 27-38 (middle) and 39-49 years (late), it was found that a greater number of infertile females fell in the mid reproductive age group $(53.3 \%)$. The mean age among primary infertility was $26.87 \pm 5.14$ years and in secondary infertility was $30.40 \pm 4.75$ years. The difference between mean age was found to be statistically significant $(p=0.008)$. The overall mean age for both types of infertility was $28.63 \pm 5.22$ years. This observation is somewhat similar to that of a study from India where the mean age of infertile women was found to be between 27.5 \pm 9.2 years in non-Khairwar scheduled tribes and $31.3 \pm 8.9$ years in Khairwar tribes. ${ }^{7}$

In age group 27-38 years, secondary infertility was found to be more common (65.6\%). The group of $15-26$ years had $25(41.7 \%)$ subjects, of which $18(72 \%)$ had primary infertility. This shows that significant association exists between age and type of infertility $(\mathrm{p}=0.016)$.

When mapped against the smaller geographical units of eastern part of north India, it was found that $70 \%$ of couples with infertility belonged to eastern U.P, probably because the catchment hospital is situated in this region and hence easily accessible to patients. A greater number of cases need to be analysed to see whether this observation persists.

Looking at the socioeconomic stratification of the study group based on the Kuppuswamy scale, it was found that $60 \%$ of couples with infertility were from the middle socioeconomic status with an equal preponderance of primary and secondary infertility. The least number of cases were from the lower socioeconomic status $(11.7 \%)$ where primary infertility was more common $(71.4 \%)$. This low number of cases is probably because of the inability to access health services by the lower socioeconomic group and lesser the need to do so with at least one living child (secondary infertility).

Studies have implicated abnormal BMI as a risk factor as it impacts the female reproductive system by contributing to anovulation, irregular menses, adverse oocyte quality, endometrial alterations, and hormonal imbalances that 
ultimately result in female infertility. ${ }^{11}$ Literature shows that in males, elevated BMI does not significantly influence semen quality, ${ }^{12}$ however, high blood pressure, which may be a consequence of long standing abnormal BMI, is a highly prevalent but an unrecognised condition in primary infertile men. ${ }^{13}$ In our study, a surprising result was that $73.3 \%$ cases of female infertile partners from eastern part of north India actually had normal BMI of which there was an equal distribution of primary and secondary infertility which shows that it did not impact as a risk factor. There were only $26.7 \%$ cases of female infertility with abnormal BMI wherein primary infertility dominated. This result is in direct contrast of what is commonly believed and needs further evaluation.

Another risk factor delineated in the study was the number of years since marriage or time to pregnancy. ${ }^{14}$ Among the 2 groups, that is $<3$ years and $\geq 3$ years, the second had 52 cases of infertility (86.7\%). This is probably because most of the couples coming to this hospital were already undergoing some form of treatment elsewhere and were referred after failure to conceive on treatment. Therefore, this result also needs further study and evaluation.

In the current study, when female infertile partners were assessed with regards to their menstruation status it was found that abnormal menstrual flow could not be attributed as a risk factor since patients with scanty flow or amenorrhoea were equal in number to those who had no menstrual problems $(\mathrm{p}=0.96)$ and only a few had excessive bleeding. However with regard to menstrual cycles, it was seen that though the 2 groups of females having regular and irregular cycles had an exactly equal number of infertile females, the ones with regular cycles had predominantly primary infertility $(70 \%)$ and those with irregular cycles had more of secondary infertility $(66.7 \%)$. This difference was found to be statistically significant $(\mathrm{p}=0.009)$. Since regular cycles usually denote a normal hypothalamic pituitary ovarian axis, the cause of primary infertility could be more of tubal/endometrial origin or a predominant male factor. With irregular cycles, the cause of secondary infertility could be more of ovarian or hormonal origin.

So in this study, it was seen that the geographical area of eastern U.P. from North India yielded $70 \%$ of the couples with infertility. Amongst all couples analysed, $60 \%$ were from the middle socioeconomic status and most presented $\geq$ 3 years for treatment. The middle reproductive age of 27-38 years and irregular menstrual cycles were found to be significantly associated with secondary infertility whereas primary infertility was associated more with the lower reproductive age group of 15-26 years and regular menstrual cycles. Other variables undertaken for analysis in the study such as BMI and menstrual flow were not significantly associated.

\section{Conclusion}

In this pilot study, a number of parameters were assessed as possible risk factors for types of infertility. Due to the relatively small number of cases, many variables did not yield significant results and therefore were not discussed. However, a significant association of primary and secondary infertility was found with age and cyclicity of menstruation and these may be considered as potential risk factors for types of infertility.

\section{Conflict of Interest: Nil.}

\section{References}

1. Zegers-Hochschild F, Adamson GD, de Mouzon J, Ishihara O, Mansour R, Nygren K, Sullivan E, Vanderpoel S.

"International Committee for Monitoring Assisted Reproductive Technology; World Health Organization" Fertil Steril. 2009;92(5):1520-1524.

2. Mascarenhas MN, Flaxman SR, Boerma T, Vanderpoel S, Stevens GA. "National, regional, and global trends in infertility prevalence since 1990: a systematic analysis of 277 health surveys." PLOS MED. 2012;9(12):e1001356.

3. Meng Q, Ren A, Zhang L, Liu J, Li Z, Yang Y. "Incidence of infertility and risk factors of impaired fecundity among newly married couples in a Chinese population" REPROD BIOMED ONLINE. 2015:30(1):92-100.

4. Wellons MF, Lewis CE, Schwartz SM, Gunderson EP, Schreiner PJ, Sternfeld B. "Racial differences in self-reported infertility and risk factors for infertility in a cohort of black and white women: the CARDIA Women's Study" Fertil Steril. 2008;90(5):1640-1648.

5. Sharma R, Biedenharn KR, Fedor JM, Agarwal A. "Lifestyle factors and reproductive health: taking control of your fertility" Reprod Biol Endocrinol. 2013 Jan 11: 66.

6. Obesity: preventing and managing the global epidemic. Report of a WHO consultation. World Health Organ Tech Rep Ser. 2000;894:1-253.

7. Kumar D. Prevalence of female infertility and its socioeconomic factors in tribal communities of CentralIndia. Rural and Remote Health. 2007;7(2):456.

8. Bennett LR "Infertility, Adoption, and Family Formation in Indonesia." Med Anthropol. 2018;37(2):101-116.

9. Kazemijaliseh H, RamezaniTehrani F, Behboudi-Gandevani S, Hosseinpanah F, Khalili D, Azizi F. "The Prevalence and Causes of Primary Infertility in Iran: A Population-Based Study." Glob J Health Sci. 2015;7(6):226-232.

10. Sarkar S, Gupta P "Socio-Demographic Correlates of Women's Infertility and Treatment Seeking Behavior in India." J Reprod Infertil. 2016;17(2):123-132.

11. Imterat M, Agarwal A, Esteves SC, Meyer J, Harlev A "Impact of body mass index on female fertility and ART outcomes." Panminerva Med. 2018 Jun 28.

12. Rufus O, James O, Michael A "Male obesity and semen quality: Any association?" Int J Reprod Biomed (Yazd). 2018;16(4):285-290.

13. Cazzaniga W, Capogrosso P, Ventimiglia E, Pederzoli F, Boeri L, Frego N, Abbate C, Alfano M, Viganò P, Montorsi F, Salonia A "High Blood Pressure Is a Highly Prevalent but Unrecognised Condition in Primary Infertile Men: Results of a Cross-sectional Study. Eur Urol Focus. 2018 Aug 3.

14. Polis CB, Cox CM, Tunçalp Ö, McLain AC, Thoma ME "Estimating infertility prevalence in low-to-middle-income countries: an application of a current duration approach to Demographic and Health Survey data." Hum Reprod. 2017;32(5):1064-1074.

How to cite this article: Chaubey L, Singh T.B, Kaithwas K, Doharey N, Peddappolla S. C. Risk factors associated with primary and secondary infertility in eastern part of north India: A pilot study. J Community Health Manag. 2018;5(4):188-191. 